\section{All Access: Better Fits for Architecture}

Julia McMorrough

University of Michigan
In 1975, disability activist Victor Finkelstein modestly but pointedly proposed an "imaginary example which turns the world upside down," ${ }^{1}$ where wheelchair users lived together in a village no longer obliged to accommodate the able-bodied, who found themselves comparatively disabled by their ill fit into their surroundings. That same year, Peter Eisenman's pointedly disorienting House VI was completed, intentionally confounding inhabitation by even the most robust physical specimens. Nearly two decades earlier, in 1956, Selwyn Goldsmith contracted polio in the same year he earned his degree from the Bartlett School of Architecture. With his drawing hand paralyzed, his life and career had to adjust themselves accordingly. His life's work would engage his insights into both realms architecture and disability - and in his seminal work, Designing for the Disabled, he upended established views on 'medical disability,' exposing instead the idea that architecture was responsible for the creation of disabling environments, and, further, that "the architect can prevent people from being disabled when they use buildings."

\section{THINKING ABOUT THESE THINGS}

This paper explores architecture's relationship with disability and accessibility, through a recent pedagogical effort at the University of Michigan Taubman College of Architecture and Urban Planning. The work was predicated on two strong hunches: one, that students can leave school well-versed in designing for disability; and two, that architecture, in turn, can be more innovative and inventive when asked to respond more expansively to issues of accommodation.

Key to this effort was establishing an environment in which students not only learned about issues of disability and accessibility, but could do so in a way that they could not, effectively, un-see what they had seen. In other words, when moving forward in their educational and professional lives, they would have no excuse for claiming ignorance as designers.

Within Taubman College, such an atmosphere was already being established, through the student-led Initiative for Inclusive Design, which, in 2017, invited two disability activists, Mieko Preston and Celeste Adams, to present their lecture "Segregated Spaces," to the college. The lecture was impactful and memorable, but ended in multiple laments on architecture's inability to meet disability on more productive terms. Though well attended, this seemed like something more students should hear. In my capacity as coordinator of a 15-section graduate studio the following fall, I asked the lecturers to present again to over 200 students and faculty, with a goal to sidestep dry and abstract lectures about ADA rules, and get right to the point as memorably and efficiently as possible.

Preston and Adams' lecture echoed sentiments by U.S. Senator Tammy Duckworth, who lost both legs in service in Iraq. In an Op-Ed to the Washington Post, Duckworth wrote: "an incline that is a few degrees too steep or an entrance that is a few inches off the ground can determine whether I am able to access an area without assistance...I understand that not everyone thinks about these things because, for most of my adult life, I didn't either. But the truth is that everyone, whether they realize it or not, is just one bad day away from needing accessible options to help them get around 
their community." ${ }^{3}$

One year later, in Fall 2018, the same students who had heard that lecture the previous year were invited to work on issues of accessible design as their thesis projects in the "All Access" thesis studio, which proposed that, in thinking about these things, and in bringing to the forefront our ideas about design for accessibility, we ask architecture to lead instead of follow. By not defaulting to a delayed reaction to accommodation, we proposed that architecture has the opportunity to become more, and not less, inventive.

\section{DEFINING ACCESSIBILITY}

The thesis course was set up as a year-long effort, with the first semester (Fall 2018) dedicated to a research seminar, and the second semester (Winter 2019) as a full-blown architecture studio. We began the seminar with exploring evolving attitudes of design for accessibility through efforts that have often run counter to parallel architectural histories, in order to better understand architecture's present and future stake in accommodation. This work saw accessibility in two ways.

First, an accessible thing is 'able to be reached or entered.'4

The ADA - the Americans with Disabilities Act - marks significant progress in designing for accessibility, and is one way to understand the letter of the law - or the what, but has insufficiencies, including in portraying the spirit, or the why and the how. In 1988, the ADA was introduced to the US Congress, and was soon passed in the Senate, but was held up for two years in the House of Representatives.

Until, in March 1990, over a thousand fed up disability rights activists descended on the U.S. Capitol, 60 of whom discarded their wheelchairs and crutches to crawl up the 83 steps to the entrance of the Capitol. The Capitol Crawl was a defining moment that finally forced the passage and then signing of the ADA on July 26 of that year. Photos of the crawl, depicting this physical and emotional struggle, succinctly capture the spirit of the necessity of the ADA, and illustrate how difficult it can be to understand something you don't see - and to see something you don't understand.

In our work in the class, we also prioritized a second definition of accessibility: one that is "friendly and easy to talk to; approachable." ${ }^{5}$ This cut many ways for our purposes in the studio, especially as we repeatedly confronted the difficulty many have with understanding, or 'seeing,' accessibility as something beyond an unwanted necessity. While working to make architecture that is approachable, we needed first to make the general topic friendly and easy to talk to - we needed to look at the topic in a fresh way, so we sought allies elsewhere.

\section{FRIENDLY}

Approachability is not an obvious initial reaction to seeing abstract painter Ad Reinhardt's black canvases, which he began producing in the 1950s, at the end of his career, and which he called the "ultimate" paintings - in his view, they were the last paintings that anyone could make.
A New York Times review of a recent showing of Reinhardt's work has noted: "[the canvases] require two things of an interested viewer: to be present and be willing to spend time." But, "Stay awhile, concentrate, and details emerge: a whisper of color, a specter of geometry. The paintings, it turns out, are alive, vibrant even." ${ }^{\prime \prime}$

However, these were also easy targets for mockery in the 50 s. Cartoonists of The New Yorker, for instance, found much to ridicule. Ironic, given Reinhardt's strong commitment over his career to his own oeuvre of cartoons as a medium for accessible didacticism, including a 25-part series about art called "How to Look," published in assorted journals and tabloids. Artist Robert Storr writes: "Reinhardt's art cartoons were the weapons with which he defended his faith in art's purity against any and all who would gussy it up, drag it down, or mock it when art was true to itself." Storr saw these cartoons as "painting's bodyguards."...stating: "Where others may have been pompous, Reinhardt was incredibly light and sharp." ${ }^{8}$

Not unlike art, accessibility can be a challenging topic of conversation, so Reinhardt's "How to Look" philosophy became a baseline for how we thought and talked about accessibility within our class. Our loftiest ambition was to be as 'light and sharp' as possible in the work produced, to allow for an elevation of the conversation and the aesthetics around designing for accessibility.

A warm-up exercise in the first semester, "Ad it Up," asked students to use graphics to communicate complexity, and to invoke Ad Reinhardt as they illustrated chapters of Edwin Abbott's 19th century book, Flatland: A Romance of Many Dimensions. Flatland, a world existing in only two dimensions, is fun to read and difficult to visualize; the perfect foil for analyzing ways of seeing.

While many among us had previously read Flatland as a satire of Victorian repression and class structures, as well as a romp through geometry and mathematics, on this fresh reading, even without looking for it, something rather startling emerged in Abbott's text. Had we not been 'present and willing to spend time,' we might have missed an interesting, and unexpected, offhand comment in Chapter 7, "Concerning Irregular Figures," where the protagonist indignantly posed a rhetorical question regarding the imperfect irregular geometric figures in their midst: "are the houses and doors and churches in Flatland to be altered in order to accommodate such monsters?"9 Though little more was made of that question in the text, we wondered, despite the sneering tone, if Abbott had set up the prescient possibility, in 1884, of accommodation for disability, and also what else we might be missing by not looking.

\section{HIDDEN ACCESS}

In getting familiar with an array of issues that had come before us, it was unsurprising to find that the degree to which exclusionary environments are excused if created in pursuit of other goals is a conundrum not specific to architecture. Almost a century ago, U.S. President Franklin Roosevelt doggedly minimized the impact of his paralysis on his public image, cleverly re-designing the spaces around him, as well as his interaction with his surroundings. But he believed that giving the public access to the accomplishments of his accommodation would undermine his ability to lead. Thus, any physical 
evidence was continually and carefully erased and environments were repeatedly returned to "normal."

This reflected a selective resistance to ideas ahead of their time, even in a moment when wounded soldiers returning from the 20th century's two world wars brought more global awareness of disability. The negative image of disability as one of weakness was still sufficiently fraught to discourage public understanding and acceptance of accommodation. Even Timothy Nugent, founder of the National Wheelchair Basketball Association as well as, in 1948, the first university program for adults with disabilities, believed strongly in the idea that those with disabilities must bear most of the burden for rising above impediments in the built world. Nugent approved of accommodations, but wanted them to be unseen by others. As a result, the existence of his program at the University of Illinois was as groundbreaking as it was virtually invisible.

Such uncomfortable juxtapositions also expose fascinating architectural blind spots regarding accommodation. From the Vitruvian Man's influence on the Classical orders to Le Corbusier's Modulor system, architecture has had difficulty shedding its indoctrination to the virtues of designing from and for the strongest, most optimal, human form. When in fact, there is much to be discovered about the human body's idiosyncrasies and how to design for it, exemplified by the car manufacturer Nissan's specially-designed "aging suit" for testing vehicles developed for an aging population with myriad physical limitations. Consumed so often by other agendas, architecture's tacit emphasis on physical ideals has frequently neutralized the potential

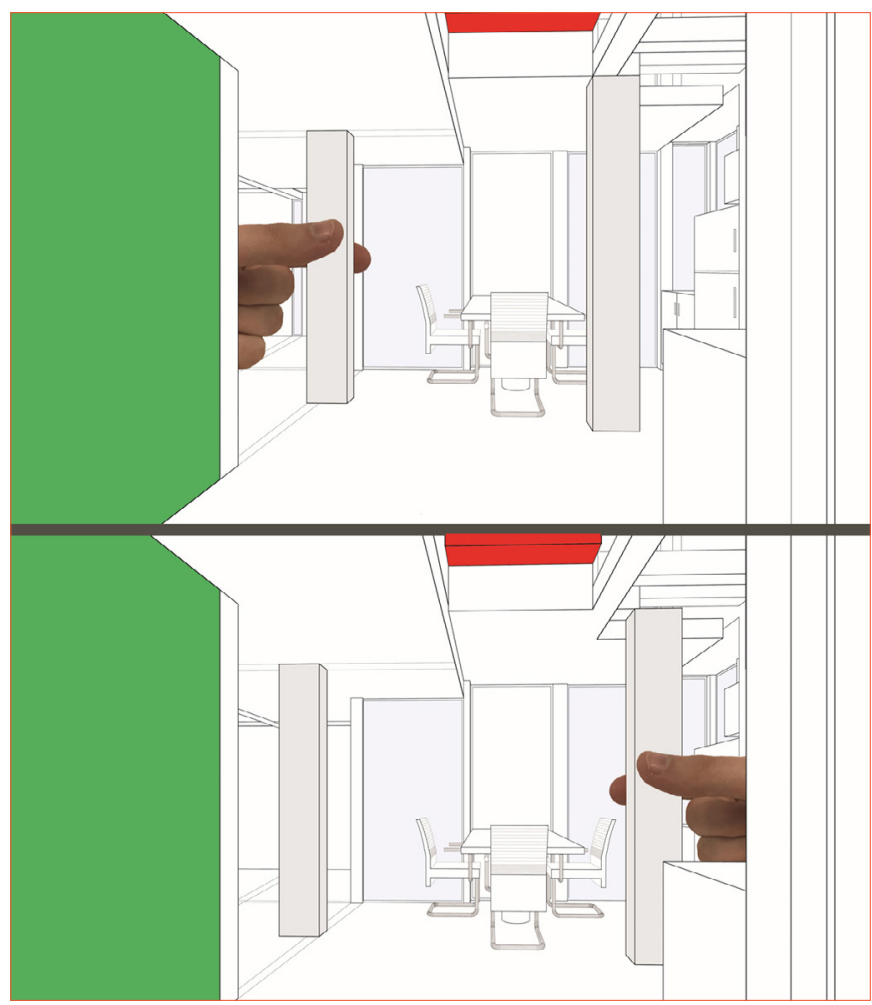

Figure 1. Better Fit for House VI - film excerpts. (Anthony Civitella)
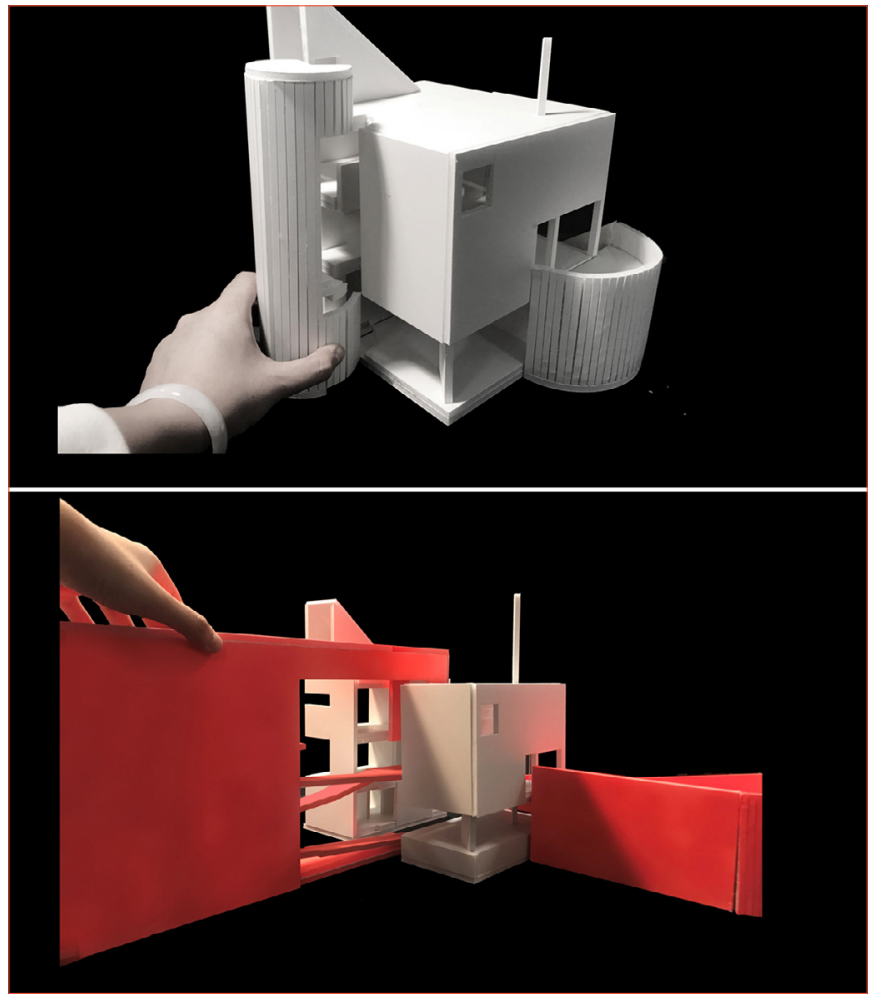

Figure 2. Better Fit for Gwathmey Residence - film excerpts. (Yiran Qiao)

of a wider definition of architecture by ignoring all but a convenient default of people who use it. But disability culture's influence on architecture picked up momentum when Selwyn Goldsmith's Designing for the Disabled took architecture to task for its complicity in the creation and promotion of disabling situations. Writer and art historian Elizabeth Guffey elaborates that it is the architecture that must make the accommodation, not the disabled user's body, and that inaccessible spaces in architecture represent a mis-fit on the part of the design, not the disabled user..$^{10}$

\section{EASY TO TALK TO}

The All Access seminar and studio worked with a trial and error approach to developing ways to make the work friendly and easy to talk to. Victor Finkelstein's text about turning things upside down gave us an inroad, prompting an exercise called "Better Fits," in which students were asked to re-imagine a canonical house, toward what they saw as a better fit for accessibility. The houses ranged from Adolf Loos' Villa Müller to Le Corbusier's Petit Cabanon, to Peter Eisenman's House $\mathrm{VI}$, and their newly-accommodating forms were depicted through a series of films, showcased as a film festival on both iconic architecture and accessible design, for the benefit of other students in the college.

Architecture studio is a unique setting where there is 
(almost nothing to lose by trying something new, and as it regards the pressures that accessibility puts on space, form, material, and society, in the winter semester studio, the students embraced the opportunity to re-consider forms accordingly. The year ended, not with answers to all questions, or solutions to all problems, but with a new set of questions to ask and possibilities to engage. Informed by their work in the research seminar, each of the twelve students proposed their own program and thesis agenda for the architecture they would design. The result was a dozen projects working individually, but also as a set - not premeditated to work together, but each somehow raising its own set of stakes for how architecture can prioritize accessibility from its inception, and each fulfilling its one part of a larger whole. Though space in this essay limits in-depth exploration of all student projects, their individual contributions warrant note, recognition, and the opportunity to explain their thesis in their own words. The All Access Thesis Studio team members were: Brian Baksa ${ }^{11}$, Sommer Cade ${ }^{12}$, Nan $\mathrm{CaO}^{13}$, Anthony Civitella ${ }^{14}$, Morgan Cook $^{15}$, Shuai Feng ${ }^{16}$, Yichen Lu ${ }^{17}$, Yiran Qiao ${ }^{18}$, Nikita Somashekar ${ }^{19}$, Pengwei Tian ${ }^{20}$, Vanessa Vedelago ${ }^{21}$, and Le Yang ${ }^{22}$.

\section{FINAL WORK}

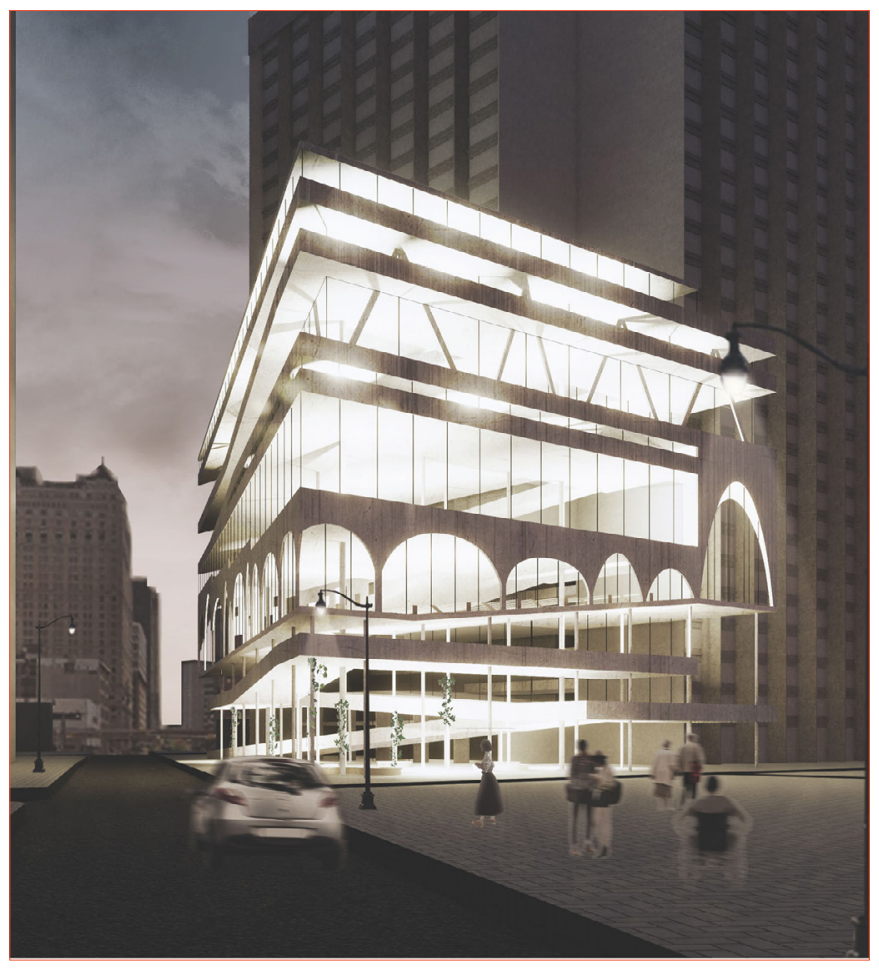

Figure 3. Into the Fold. (Yiran Qiao)

Expanding on her first semester revision to the Gwathmey Residence, Yiran Qiao exploited the function and form of inclined planes to create a vibrant multi-use structure appended to the Detroit office of the Disabled American Veterans organization. The project played with issues of 'delayed access,' exaggerating and punctuating the ramp often awkwardly applied to an existing building. But this ramp was secretly up to more than it appeared, creating a fully accessible egress path from upper levels of the existing building, thereby eliminating the dangerous and inequitable practice of requiring those who are wheelchair-bound to wait near an egress stair or elevator for help that might be (too) long in coming in a fire or other emergency.

Brian Baksa's "ADA Hacks" were developed and deployed to site-specific situations and contexts: He proposed better fits through

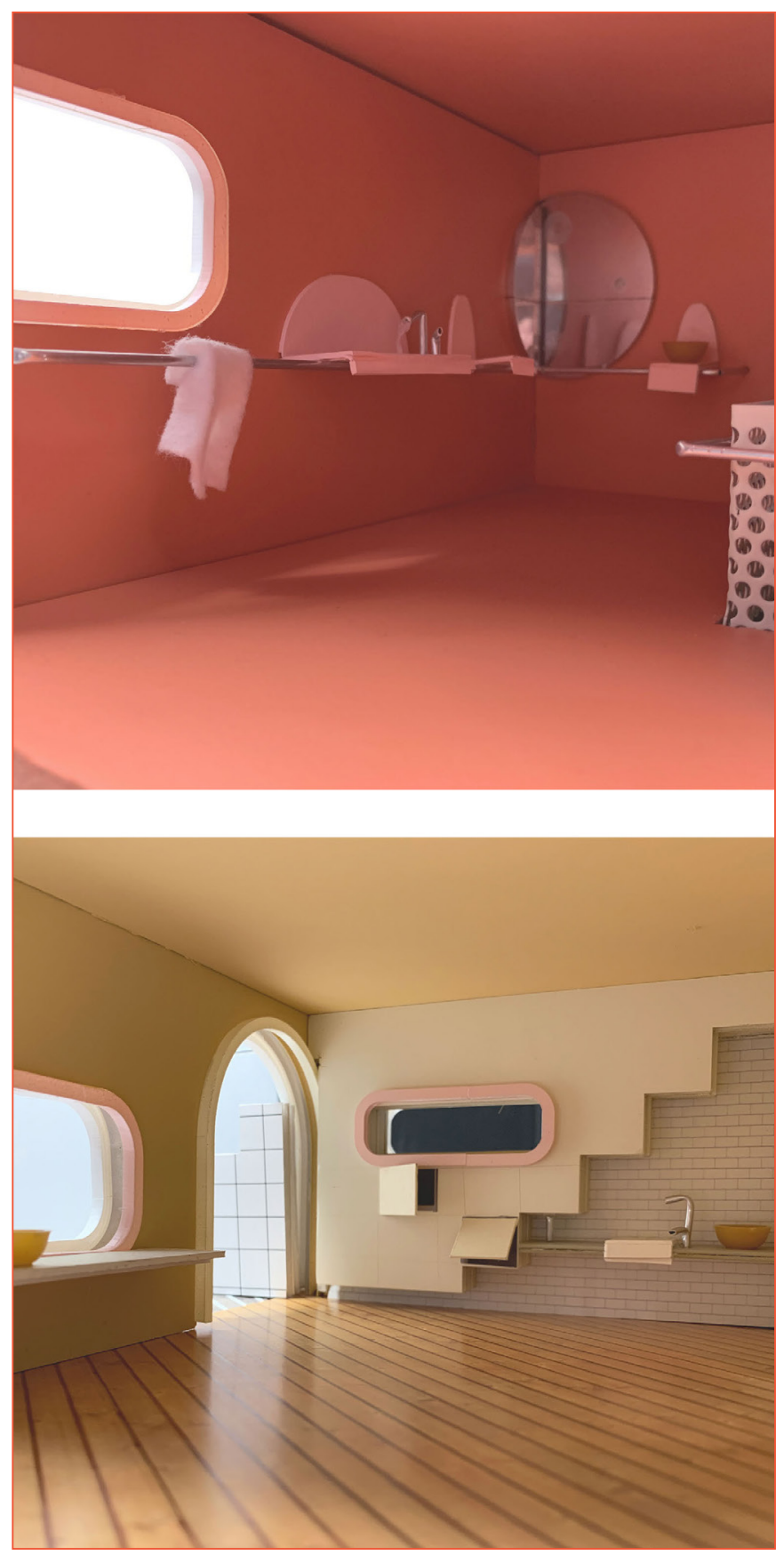

Figure 4. Action Figures as...An Addition. (Brian Baksa) 
several projects under the heading of "Action Figures," including a new set of "un-standards," an exhibition, and an accessory dwelling for attachment to any house. In each instance, defaults were questioned, not toward a dismissal, but to prompt a deeper understanding that might yield a fruitful exploitation of currently acceptable minimum guidelines. Among the questions "Action Figures" asked was why an accessible accessory dwelling couldn't be more fun, social, functional, beautiful and inviting than the more typically normative house it accompanies.

Morgan Cook proposed a "Mobile Access" system of movable dwellings that could address numerous disabilities and needs. For

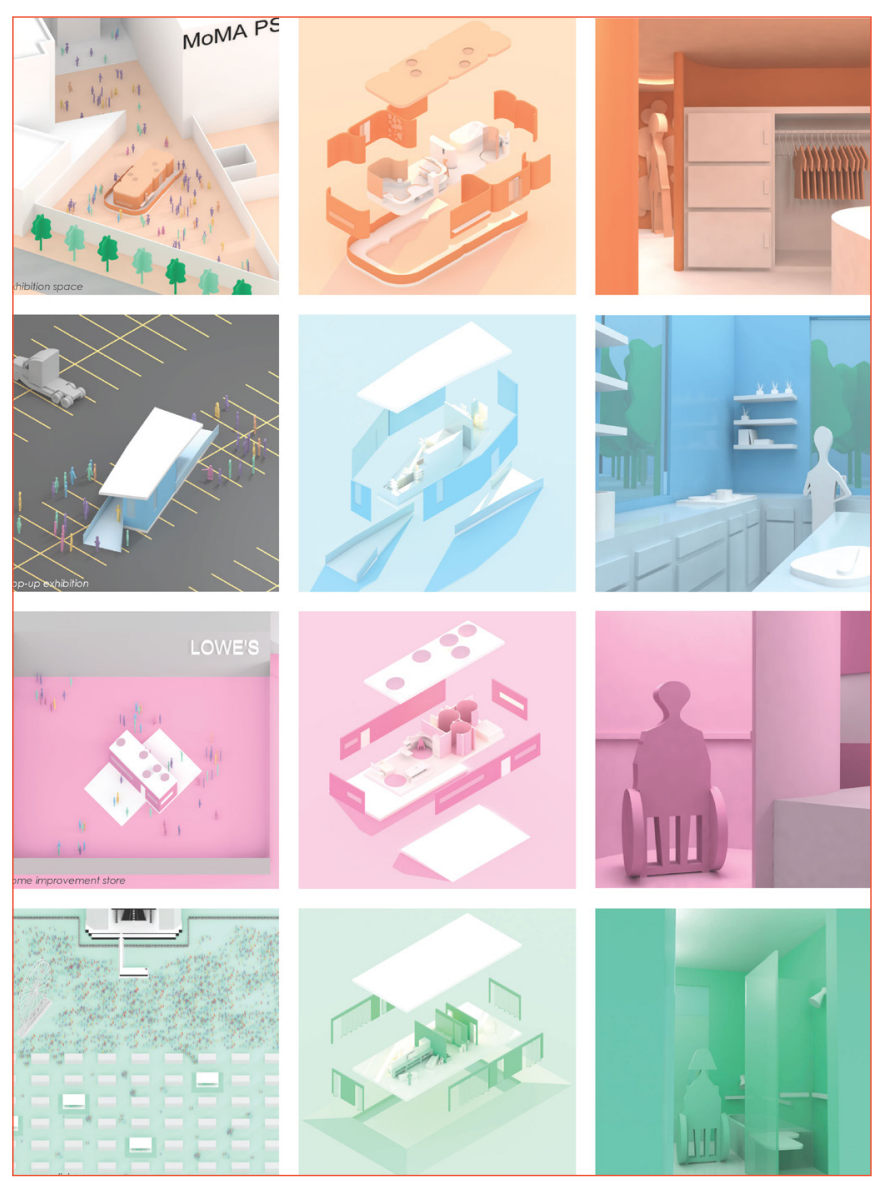

Figure 5. Mobile Access - taxonomy. (Morgan Cook)

living, but also serving didactic and exhibition purposes. Fun, exciting, and mobile, these units can travel far and wide, meeting a wide array of audiences wherever they are. The project, which also included development of a set of collectibles and a toy house, was ostensibly about discrete domestic spaces, but also proposed a strategic broadcasting of innovative ideas about accessible design to as vast and varied an audience as possible. It is notable to the thesis of the studio that Cook's project was chosen by visiting reviewers to reresent the All Access studio in the competition for studio thesis prize,

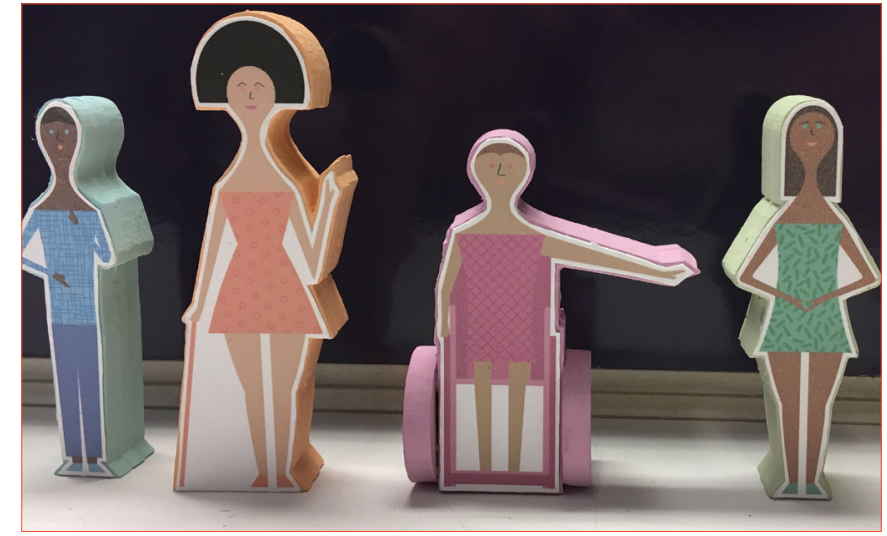

Figure 6. Mobile Access toy figures. (Morgan Cook)

where "Mobile Access" was awarded second place overall, in a graduating class of 180 students.

As a set, each of the twelve projects in the studio illustrated how accessibility is not one thing: it is physical, social, legal, spatial, perceptible, and imperceptible. The studio strove to achieve its own thesis prompt - that students can be well-versed in this topic and that the architecture could transcend diminished expectations for accessible design. The ultimate test of this thesis would be the final review. The challenge for the students was to make the topic of accessibility 'friendly and approachable' enough that it did not derail other conversations about the design work.

The anxiously anticipated final review day was full of unexpected conversations and insights. Many reviewers later reported that they had come away thinking differently about how they understand and engage accessibility in their own work, and the language they use to discuss it. One reviewer reported back that she found herself bringing accessibility into the conversation repeatedly on reviews the next day at another school - simply because she couldn't stop thinking about it. She couldn't un-see what she had seen.

The All Access studio has reacted to architecture's historically delayed reaction to accessibility by exploring the hunch that architectural education is ideally situated to invent productive protocols that not only eschew defaults, but also allow the academy and the profession to rise to new occasions. It's the ability to navigate and accommodate emerging issues in a capacity that transcends the perception of limitation that is one of architecture's significant powers. Accordingly, the All Access studio was framed not as a lament, but as an optimistic exploration of possibility.

\section{Notes}

1. Victor Finkelstein, "Discovering the Person in Disability and Rehabilitation," Magic Carpet Vol. XXVII (1975), 31-38.

2. Selwyn Goldsmith, Designing for the Disabled: The New Paradigm, (New York: Architectural Press, 1997) 152.

3. Tammy Duckworth, "Congress wants to make Americans 
with disabilities second-class citizens again," Washington Post, October 17, 2017, https://www.washingtonpost.com/ opinions/congress-is-on-the-offensive-against-americanswith-disabilities/2017/10/17/f508069c-b359-11e7-9e58e6288544af98_story.html.

4. Google Dictionary

5. Google Dictionary

6. Holland Cotter, "An Abstractionism Shaped by Wounded Ideals: Ad Reinhardt at the David Zwirner Gallery," New York Times, November 21, 2013, https://www.nytimes. com/2013/11/22/arts/design/ad-reinhardt-at-the-davidzwirner-gallery.html.

7. Robert Storr, "Diogenes of the Funny Pages," in How to Look: Ad Reinhardt Comics, ed. Kristine Bell and Anna Gray (Berlin: Hatje Cantz, 2013), 5-19.

8. Robert Storr.

9. Edwin Abbott, Flatland: A Romance in Many Dimensions (London: Seeley \& Co., 1884), 32.

10. Elizabeth Guffey, Designing Disability: Symbols, Space, and Society (London: Bloomsbury Academic, 2018), 3-5

11. Action Figures (student: Brian Baksa): "Poltical action, social action, and cultural action. These are all elements embedded in architectural space and with each construction detail we produce, a social consequence emerges. While ADA Standards (design regulations detailing accessible space) mark a leap in equity among those with mobility impairments, the restrictive nature of the documents and their oversighted, cultural narrative lend themselves more to architectural afterthought than to creative design interventions. Action Figures is a situational and episodic exploration into the latent and untapped social, cultural, and political potentials that exist within accessbility standardization. This thesis proposes misusing ADA Standards in a way that might generate new, unqiue spatial logics; resulting in a celebration of oddity, strangeness, and difference."

12. All Access Common Sense (student: Sommer Cade): "This thesis focuses on a Museum of the Senses to explore sense as a tool to design for all and to explore and question the use or dismissal of sense in architecture. This exploration takes place through spaces which emphasize or repress certain senses, meant to speak to both the increased amount of experience which can occur and the lack of sense creation within architecture. By designing for all senses, the architecture becomes inherently accessible, in the way that access can be defined as being able to intake knowledge. Sparked through the questions of, "What happens when you cannot see art?" and "What is experience without sight?" this thesis has expanded to questioning how to design for all users and to questioning the experience of an able-bodied user by emphasizing or rejecting certain sense-related spatial solutions. By focusing on senses, this thesis focuses on user experience with the inherent quality of accessibility in terms of both communication and physical access."

13. All Access Illumination (student: Nan Cao): "This thesis project is about designing a meditation space run by visually impaired employees. The space is designed for the whole-spectrum of the blind as well as the visually impaired. The idea of this thesis among disability design topics is to rethink architectural design from the perspective of visual impairment. If we think the way blind people see the world and try to design the world in which blind people can actually "see", it would be an interesting research topic."

14. Access is More, Adaptable Homes for a Lifetime (student: Anthony Civitella): "Due to a lack of housing opportunities, an inequality of employment and income exists between people with a disability and able-bodied users in the United States. Only the bare minimum of accessible housing is accounted for, if not completely avoided. In turn, the built environment only provides two types of homes: houses built biasing able-bodied users, and custom homes that are fully ADA accessible. This thesis investigates a new typology of homes that are designed to be adaptable for longevity by challenging conventional homes which bias either an able-bodied user or disabled user. Through the lens of modernism, the complexity and reality of accessibility will juxtapose with modernism's characteristics to produce homes that fit any user's ability."

15. Mobile Access (student: Morgan Cook): "This thesis explores the intersectional domestic needs of abled and disabled users in the form of traveling exhibitions that not only educate visitors, but also expand how we think and design for accessibility. Although we can appreciate how ADA standards and universal design have raised awareness for inclusive design, neither are overall solutions. Both recognize user differences, but ADA standards have a surplus of solutions to fit varying needs while universal design searches for one solution that makes us all the same. How can design celebrate our intersectionalities without over-complicating them? What does this middle look like? Mobile Access utilizes traveling exhibitions in order to distribute information to everyone everywhere. Starting from the parameters of a mobile home, i.e., size, transportability, and floor plan, multiple design solutions explore residential accessibility at varying scales. With a variety of design options and scales as well as a small residential focus, these exhibitions can go anywhere."

16. All Access Pre-school, Let's All Play (student: Shuai Feng): "An accessible pre-school offers benefits for all children. For children who have mobility or other challenges, an accessible playground allows them to play. And it's not just children who benefit. We tend to think that it's the child who needs to be accommodated. Yet there are far more parents and grandparents with disabilities than children. Crossgenerational play is imperative to building strong families. Adults who have mobility issues can benefit from wheelchairaccessible playgrounds because these designs allow them to go there with their child and spend time together."

17. All Access Retreat, A Place to Hang Out (student: Yichen Lu): "Accidents happen, and this project is designed primarily for those who are newly disabled, providing a gathering space and a supplementary rehab center (near a hospital) that provides support, information, consultation as well as practical training 
to help people pass through this life transition. Architecturally, this thesis explores the ability of architecture to uplift people physically and psychologically by utilizing natural elements, landscape, and boundaries between interior and exterior to pursue a positive and caring environment that satisfies both patients and staff."

18. Into the Fold (student: Yiran Qiao): "In architecture, both stairs and ramps provide vertical transition. However, a stair separates one story from another; while a ramp connects. In architecture, the form of a stair, with its steps and angle of rising from one level to another, acts to reinforce the distinction between two levels. Compare it to a ramp, which, as a sloping plane, tends to feel like a linking of two floors or areas. Ramps are not just pragmatic or functional elements in buildings. They can often be used to perform symbolic or ritualistic roles. From the psychological perspective of the disabled, they have often supported the view that disability was an abnormal or shameful condition; they have reinforced the difference between able-bodied action and disabled action. Since for the disabled, the difference between being on the ramp and on the flat land is subtle, why not merge these two kinds of feeling? The idea presented here is about considering the nature and continuity of the relationship between different levels in a project and how the choice of vertical circulation can be used to enhance that relationship."

19. Sight Sense Line (student: Nikita Somashekar): "Twenty percent of the US population has some form of disability, but $95 \%$ of the roles written for a disabled person are played by able-bodied persons. Out of 1646 seats, 4 are designated for differently abled bodies. This is today's reality. The proposed thesis is aimed at exploring the reconfiguration of a performance space to stage the emerging performing arts group with mixed-ability. In the field of performance art, an artist with any form of disability is seen as an inspiration, because they have overcome their 'disability' to perform what an able-bodied person can do. But this is not what they want. Their ability to perform using their strengths only reconfigures the art. Paralympics has seen the development and evolution of different sports based on multiple different abilities and differently-abled bodies. Similar reconfiguration is not yet seen in the spectrum of performance arts. This project proposes to form a platform to cater to the development of art forms rather than form restrictions. The fact that in the absence of one sense the other senses are elevated is used. Different elements to celebrate the 'other senses' are provided."

20. All Access Water - Venice (student: Pengwei Tian): "This thesis analyzes the possibility of designing a getaway and enjoyable space for physically disabled people, since many are not able to enjoy vacations that have special contexts that contribute to further inaccessibility. Venice is very special in an environmental setting where water flows through the entire city, and the water transportation is super crucial to both the visitors and the local citizens. Digging deep into the water scene, Venice has different types of boats, and different ways of loading. However, most of the loading spaces are not wheelchair accessible. This project uses architecture to make every loading dock into an accessible spot for wheelchairs. It also suggets a new genre of boat so that those in wheelchairs can be comfortable on them."

21. All Access Play Surface 1: Ground Figure (student: Vanessa Vedelago): "Currently, the relationship with the accessibility of surfaces, including the ground, can sometimes be thought of and defaulted to as a flat surface. Regarding this, a flat surface is thought to be the most accessible, but this puts able-bodied users at a higher visual level than disabled users, and lends the surface to be thought of as boring. The ground is the one horizontal surface which we (and animals) constantly touch, whether with our feet, canes, wheels, paws and others, but its influence on the user can make the environment disabling. The ambition of this project seeks to challenge this relationship in the form of a new ground in order to explore perspectives in which we communicate between one another, our bodies, and "play." The playground aspires to achieve points of equitable exchange, allowing the ground itself to act as a reorienting device in hopes of giving the urban environment a playful, accessible and scaled surface for all ages. Nested in the courtyard of the MoMA PS1, the system comes to the forefront as a new playscape and moment of transition into the current museum."

22. All Access Gymnasium Inclusive Fitness Facilities Design (student: Le Yang): "For years, the disabled community has been viewed by a segment of society as a group that requires special attention and necessary care instead of inclusion. This kind of institutionalized thinking saw many people become internalized over time. Rather than thinking of disabled people as a group requiring special assistance, this thesis proposal imagines disabled users as a group of people full of imaginative independence. Actually, some disabled people perform better than able-bodied people in some fields, like sports. All Access Gymnasium is starting from the perspective of a disabled user, by exploring the fact which is common sense to a disabled user, but which able-bodied people rarely know. All Access Gymnasium will unveil the world of disability layer by layer, such as the varieties of wheelchairs, some of the most popular wheelchair sports and its corresponding wheelchair types, available here for loan and use. 